Pak. j. sci. ind. res. Ser. B: biol. sci. 2021 64B(1) 13-17

\title{
Efficient Protocol for In vitro Regeneration of Ocimum sanctum using Nodal Segments as Explants
}

\author{
Hammad Afzal Kayani ${ }^{\mathrm{a}, \mathrm{c}}$, Mariam Raziq*a,d, Syeda Kahkashan Kazmi, \\ Sheeba Naz ${ }^{\text {a,f }}$ and Saifullah Khan ${ }^{\mathrm{a}, \mathrm{b}}$ \\ ${ }^{a}$ Biotechnology Wing, International Center for Chemical and Biological Sciences, University of Karachi, Pakistan \\ ${ }^{b}$ Department of Agriculture, University of Karachi, Pakistan \\ ${ }^{\mathrm{c} B i o s c i e n c e s ~ D e p a r t m e n t, ~ S h a h e e d ~ Z u l f i k a r ~ A l i ~ B h u t t o ~ I n s t i t u t e ~ o f ~ S c i e n c e ~ a n d ~ T e c h n o l o g y ~(S Z A B I S T), ~}$ \\ Clifton, Karachi, Pakistan \\ ${ }^{\mathrm{d} B i o m e d i c a l ~ E n g i n e e r i n g ~ D e p a r t m e n t, ~ S i r ~ S y e d ~ U n i v e r s i t y ~ o f ~ E n g i n e e r i n g ~ a n d ~ T e c h n o l o g y, ~ K a r a c h i ~}$ \\ 'Jinnah University for Women, Karachi, Pakistan \\ ${ }^{f}$ Dow College of Biotechnology, Dow University of Health Sciences, Ojha Campus, Karachi, Pakistan
}

(received January 26, 2018; revised December 12, 2018; accepted December 13, 2018)

\begin{abstract}
Ocimum sanctum commonly called (holy basil) an herb containing medicinal, ornamental values, is often used in culinary applications. This research focuses on the improved and efficient protocol for the direct regeneration and acclimatisation of Ocimum sanctum using nodal segments. Organogenesis and multiplication from explants were observed to a maximum on Murashige and Skoog (MS) medium supplemented with $0.1 \mathrm{mg} / \mathrm{L}$ of 6-Benzyl amino purine (BAP) and $0.025 \mathrm{mg} / \mathrm{L}$ of Indole-3-acetic acid (IAA). Furthermore, same medium was found effective for the induction of roots, in the in-vitro grown plantlets. A series of experiments were conducted to optimise the acclimatisation of in-vitro grown rooted plantlets of Ocimum sanctum. For this study different types of potting mix in assorted ratios were used to obtain best supporting media for the acclimatisation, A7 media containing soil : farmyard manure (75:25) and A1 media containing (100\%) sand were found best supporting medium for the acclimatisation and hardening of Ocimum sanctum.
\end{abstract}

Keywords: organogenesis, nodal segments, acclimatization, regeneration, Ocimum sanctum

\section{Introduction}

Aromatic plants have played a significant role in the combating diseases, since ancient times, including, $O$. sanctum is a great contender for new investigations due to vast array of activities (Triveni et al., 2013). Ocimum sanctum L. (holy basil) is considered a very sacred plant and rich source of essential oil (Kumar et al., 2011). The chief component is eugenol and the oil contains other chemical compounds like l- methyl chavicol, cineole, citral, 1- 8-cineole, carvacrol, $\propto$-pinene, eugenol, eugenol methyl ether, methyl eugenol, $p$-cymene, linalool, bornyl acetate, and eugenol (Kothari et al., 2004). Essential oils and herbal extracts have great potential as natural flavours and enormous uses in traditional practices. Ursolic acid is the principal component of the $O$. sanctum (tulsi) leaves (Shanmugam et al., 2013; Fontanay et al., 2008). O. sanctum used in various purposes such as leaves, flowers, stem, root, seeds etc. are known to have potential pharmacological activity. It also plays a significant role in treatment of fevers, arthritis, convulsions, bronchitis etc. in traditional medical practices (Kumar et al., 2011).

*Author for correspondence;

E-mail: mariam.raziq@yahoo.com
Therapeutically, $O$. sanctum is used for treatment of eye diseases and its oil also helps in eye sight improvement (Rajeswari, 1992), while its extract have been shown to possess antimalarial, insectical and larvicidal activity (Kumar et al., 2011). It also has anthelmintic (Sen, 1993), antidiabetic (Hannan et al., 2015), analgesic, antioxidant (Khanna and Bhatia, 2003; Rajeswari, 1992), immunemodulatory (Jeba et al., 2011), antiulcer (Dharmani et al., 2004), hepatoprotective (Chattopadhyay et al., 1992) and anti-inflammatory activity (Malick, 2014).

There are previous reports available on $O$. sanctum invitro propagation using other explants sources, but this is the first report of in-vitro multiplication using nodal segments as explants. The main rationale of this study was to develop a sterile germ-plasm source that can be used for other in-vitro studies like bio-transformation (Zafar et al., 2012) and protoplast manipulations.

\section{Material and Methods}

Plant material. Seeds were collected from the $O$. sanctum plants grown in the green house of International Center for Chemical and Biological Sciences (ICCBS), University of Karachi. 
Sterilization. Seeds of $O$. sanctum were surface sterilized using 20\% (v/v) commercial bleach in autoclaved distilled water for $20 \mathrm{~min}$ with continuous shaking. Two drops of Tween-20 were also added with the sterilant as a surfactant. The seeds were then sieved through a pre-sterilized tea strainer and rinsed thrice with autoclaved distilled water in a petri-dish (Khan et al., 2008). Finally, seeds were placed on a filter paper in a petri-dish to remove moisture. The entire experiment was performed in a laminar flow cabinet.

Seed germination. For germination, MS medium (Murashige and Skoog, 1962) was used with $25 \mathrm{~g} / \mathrm{L}$ sugar and $6 \mathrm{~g} / \mathrm{L}$ agar without plant growth regulators (PGRs). The $\mathrm{pH}$ of the media was adjusted to 5.75 before autoclaving. Media sterilization was performed by autoclaving at standard temperature and pressure $\left(121^{\circ} \mathrm{C}, 15\right.$ p.s.i., and $\left.15 \mathrm{~min}\right)$. The seeds were transferred to the germination media and the cultures were kept under 16:8 photoperiod provided by white fluorescent light (1000 Lux) at $25 \pm 1{ }^{\circ} \mathrm{C}$ for 4 weeks.

Shoot induction and multiplication. Nodal segments $(1-2 \mathrm{~cm})$ of Ocimum sanctum were taken from the seed germination medium under aseptic condition. 28 days old nodal segments were cultured on shooting and multiplication medium.

The media were corresponding with the formulation of MS medium containing BAP and Kinetin (KN) in various concentration having media code OS1 - OS8 as shown in Table 1. MS medium was considered as control without growth regulators. All the cultures were incubated at $25 \pm 1{ }^{\circ} \mathrm{C}$ with $16: 8$ photo periods. Data of the plant growth parameters i.e., shoot regeneration; average number and length of shoot were recorded weekly for five consistent weeks.

Root induction. For In vitro root propagation, Ocimum sanctum shoots were taken on various roots induction media in order to propose an optimized medium for root induction shown in (Table 2) The media was formulated with MS media containing various kinds of auxins IAA, 1-naphthelene acetic acid (NAA) and indole-3-butyric acid (IBA) individually, and in combination with varied concentration (Table 2). In this experimental setup, Ten different combinations bearing media code OR1 to OR9 were used, while basal MS medium with no growth regulators was control.

Auxin-cytokinin combination media. To test the effect of auxin:cytokinin combination medium on the plant growth, viz-a-viz shooting and rooting, an experimental
Table 1. Effect of cytokinins on shoot induction in $O$. sanctum

\begin{tabular}{llllll}
\hline \hline Code & $\begin{array}{l}\text { Cytokinin } \\
(\mathrm{mg} / \mathrm{L})\end{array}$ & $\begin{array}{l}\text { \% Shoot } \\
\text { regeneration/ } \\
\text { explant }\end{array}$ & $\begin{array}{l}\text { No. of } \\
\text { shoots* }\end{array}$ & $\begin{array}{l}\text { Average shoot } \\
\text { length }(\mathrm{cm})^{*}\end{array}$ \\
\cline { 2 - 4 } & BAP & $\mathrm{KN}$ & & & \\
\hline MS & 0.0 & 0.0 & 54 & $2.73 \pm 0.34$ & $1.80 \pm 0.24$ \\
OS1 & 0.05 & 0.0 & 87 & $9.98 \pm 0.09$ & $4.93 \pm 0.15$ \\
OS2 & $\mathbf{0 . 1}$ & 0.0 & $\mathbf{1 0 0}$ & $\mathbf{1 1 . 0 6} \pm \mathbf{0 . 2 2}$ & $\mathbf{5 . 5 3} \pm \mathbf{0 . 1 3}$ \\
OS3 & 0.25 & 0.0 & 100 & $11.00 \pm 0.23$ & $5.23 \pm 0.12$ \\
OS4 & 0.5 & 0.0 & 100 & $10.86 \pm 0.24$ & $4.96 \pm 0.15$ \\
OS5 & 1 & 0.0 & 67 & $10.46 \pm 0.23$ & $4.61 \pm 0.24$ \\
OS6 & 0.0 & 0.25 & 67 & $4.03 \pm 0.03$ & $2.30 \pm 0.18$ \\
OS7 & 0.0 & 0.5 & 75 & $4.83 \pm 0.14$ & $3.03 \pm 0.19$ \\
OS8 & 0.0 & 1 & 87 & $5.03 \pm 0.07$ & $3.96 \pm 0.07$ \\
\hline \hline
\end{tabular}

*Values are mean \pm standard error $(\mathrm{X} \pm \mathrm{SE})$

Table 2. Effect of auxins on root induction

\begin{tabular}{lllllll}
\hline \hline Code & Auxins (mg/L) & $\begin{array}{l}\text { \% Root } \\
\text { induction/ } \\
\text { explant }\end{array}$ & $\begin{array}{l}\text { No. of } \\
\text { roots* }\end{array}$ & $\begin{array}{l}\text { Average root } \\
\text { length }(\mathrm{cm}) *\end{array}$ \\
\cline { 2 - 4 } & \multicolumn{7}{c}{ IAA } & IBA & NAA & & \\
\hline MS & 0.0 & 0.0 & 0.0 & 60 & $2.06 \pm 0.33$ & $2.00 \pm 0.27$ \\
OR1 & 0.1 & 0.0 & 0.0 & 100 & $4.00 \pm 0.23$ & $4.86 \pm 0.09$ \\
OR2 & 0.5 & 0.0 & 0.0 & 100 & $4.60 \pm 0.23$ & $4.40 \pm 0.13$ \\
OR3 & 1 & 0.0 & 0.0 & 100 & $5.80 \pm 0.10$ & $3.76 \pm 0.20$ \\
OR4 & 0.0 & 0.1 & 0.0 & 93.3 & $9.93 \pm 0.18$ & $4.87 \pm 0.08$ \\
OR5 & 0.0 & 0.5 & 0.0 & 100 & $11.06 \pm 0.15$ & $5.01 \pm 0.05$ \\
OR6 & 0.0 & $\mathbf{1}$ & 0.0 & $\mathbf{1 0 0}$ & $\mathbf{1 2 . 9 3} \pm \mathbf{0 . 2 2}$ & $\mathbf{5 . 9 6} \pm \mathbf{0 . 0 3}$ \\
OR7 & 0.0 & 0.0 & 0.1 & 93.3 & $8.60 \pm 0.23$ & $4.73 \pm 0.11$ \\
OR8 & 0.0 & 0.0 & 0.5 & 100 & $9.20 \pm 0.14$ & $5.06 \pm 0.12$ \\
OR9 & 0.0 & 0.0 & 1 & 100 & $12.06 \pm 0.18$ & $5.93 \pm 0.20$ \\
\hline \hline
\end{tabular}

*Values are mean \pm standard error $(\mathrm{X} \pm \mathrm{SE})$

set up shown in Table 3 was applied under controlled environment for five weeks.

Acclimatization. Acclimatization of Ocimum sanctum plantlets was done in which different supporting materials i.e. soil, charcoal, farm yard manure (FYM) were used in different ratios and combinations as shown in Table 4.

Statistical analysis. All the parameters of recorded data for each treatment were analyzed by analysis of variance (ANOVA) in MSTAT-C software (MSTATC, 1989). Fifteen replicates were used for each treatment applied.

\section{Results and Discussion}

In this study, a modified protocol of direct regeneration and acclimatisation of Ocimum sanctum plantlets was 
Table 3. Effect of synergistic/single medium on direct regeneration in $O$. sanctum

\begin{tabular}{lllll}
\hline \hline Code BAP IAA & $\begin{array}{l}\text { No. of } \\
\text { shoots }\end{array}$ & $\begin{array}{l}\text { Average } \\
\text { shoot } \\
\text { length } \\
(\mathrm{cm})^{*}\end{array}$ & $\begin{array}{l}\text { No. of } \\
\text { roots* }\end{array}$ & $\begin{array}{l}\text { Average } \\
\text { root length } \\
(\mathrm{cm}) *\end{array}$ \\
& & & \\
\hline
\end{tabular}

\begin{tabular}{lllllll}
\hline OC1 & 0.1 & 0.025 & $12.40 \pm 0.22$ & $5.94 \pm 0.05$ & $15.00 \pm 0.23$ & $6.05 \pm 0.06$
\end{tabular}

$\begin{array}{lllllll}\text { OC2 } & 0.1 & 0.05 & 11.33 \pm 0.12 & 5.59 \pm 0.24 & 14.46 \pm 0.13 & 5.83 \pm 0.11\end{array}$

$\begin{array}{llllllll}\text { OC3 } & 0.1 & 0.1 & 10.65 \pm 0.12 & 5.38 \pm 0.24 & 13.06 \pm 0.06 & 5.10 \pm 0.24\end{array}$

$\begin{array}{lllllll}\text { OC4 } & 0.1 & 0.25 & 10.10 \pm 0.22 & 5.02 \pm 0.24 & 12.13 \pm 0.09 & 4.98 \pm 0.12\end{array}$

$\begin{array}{llllllll}\text { OC5 } & 0.1 & 0.5 & 10.03 \pm 0.26 & 4.83 \pm 0.11 & 10.93 \pm 0.06 & 4.55 \pm 0.12\end{array}$

*Values are mean \pm standard error $(\mathrm{X} \pm \mathrm{SE})$

Table 4. Acclimatization of Ocimum sanctum

\begin{tabular}{llll}
\hline \hline Code & Formulation & Ratio & $\begin{array}{l}\text { \% survival/leaf colour and } \\
\text { morphology }\end{array}$ \\
\hline A1 & Soil & $\mathbf{1 0 0}$ & $\mathbf{8 7 \%}$, green/normal \\
A2 & Charcoal & 100 & $5 \%$, green/normal \\
A3 & FYM & 100 & $50 \%$, green/normal \\
A4 & Soil: Charcoal & $75: 25$ & $70 \%$, green/normal \\
A5 & Soil: Charcoal & $50: 50$ & $60 \%$, light green/stunted \\
A6 & Soil: Charcoal & $25: 75$ & $50 \%$, light green/stunted \\
A7 & Soil: FYM & $\mathbf{7 5 : 2 5}$ & $\mathbf{8 7 \%}$, green/normal \\
A8 & Soil: FYM & $50: 50$ & $75 \%$, green/normal \\
A9 & Soil: FYM & $25: 75$ & $60 \%$, green/normal \\
A10 & FYM: Charcoal & $75: 25$ & $60 \%$, light green/normal \\
A11 & FYM: Charcoal & $50: 50$ & $50 \%$, light green/stunted \\
A12 & FYM: Charcoal & $25: 75$ & $35 \%$, light green/stunted \\
\hline \hline
\end{tabular}

optimized. The germination and development of seeds were recorded in MS medium after three weeks of culture. The auxiliary bud explants showed $100 \%$ regeneration after 21 days of culture when placed in media supplemented with auxins and cytokinins alone and in combination.

Shoot induction and multiplication. In this study, the cultured nodal segments on MS medium with cytokinins (BAP and KN) showed budding. Concentration and cytokinin type both exhibited their role in successful in-vitro growth. There are some reports of favouring KN over BAP previously (Kumar and Rao, 2007; Bhattacharya and Bhattacharya, 2001), however, Begum et al. (2000) and Gopi et al. (2006) reported direct multiple shoots differentiation of $O$. sanctum and O. gratissimum L. respectively in BAP supplemented medium. Preece (1995) stated that apical dominance and cell division due to cytokinin, influences the growth and shoot induction. The maximum induction of multiple shoots after four weeks of initiation $(11.06 \pm 0.22)$ was attained on medium $\left(\mathrm{OS}_{2}\right)$ containing $0.1 \mathrm{mg} / \mathrm{L} \mathrm{BAP}$, having $5.53 \pm 0.13 \mathrm{~cm}$ average shoot length. As the concentration got higher, the corresponding number of shoot and shoot lengths were on gradual decrement, while application of $\mathrm{KN}$ did not yield any remarkable results (Table 1).

Root induction. After four weeks, the regenerated shoots attained the height (up to $1-1.5 \mathrm{~cm}$ ). Root induction occurs when regenerated shoots were transferred on rooting media which contains MS media with different concentration of auxins (IBA, IAA, NAA) as shown in Table 2. The comparative study of different auxins shows that the root induction response is vigorous in IBA as compared to IAA and NAA. The optimum media type was thus determined. A relationship was found between the rooting percentage and number of roots in-vitro differentiated plant was found in Table 2 . The results showed that, the $100 \%$ root formation with increase in number and length was observed in OR6 medium which contains IBA $1 \mathrm{mg} / \mathrm{L}$ i.e., $12.93+0.22$ root induction and average root length is $5.96 \pm 0.03 \mathrm{~cm}$ as shown in Table 2. Concurrently, it is also observed that the effect of IAA and NAA during the induction of roots gives $100 \%$ root induction with undersized root number and length. Deklerk et al. (1997) suggested that high concentration inhibits, while lower auxin concentrations having growth stimulating effect on root induction.

Auxin. Cytokinin medium effect on plant regeneration. In third set of experiment, auxin in combination with optimized cytokinin i.e., BAP $0.1 \mathrm{mg} / \mathrm{L}$ (OC2) was evaluated to testify synergistic medium potential (Table $3)$. Emergence of shoot buds was observed on MS medium having combination of BAP and IAA illustrated the good response (Fig. 1a). It is observed that analysis of variance revealed highly significant differences in OS1 medium formulated with (IAA $0.025 \mathrm{mg} / \mathrm{L}$ and BAP $0.1 \mathrm{mg} / \mathrm{L}$ ) respectively, which showed vigorous effect on shoot multiplication (12.40 \pm 0.22$)$ and shoot length $(5.94 \pm 0.05 \mathrm{~cm})$ as observed (Fig. $1 \mathrm{~b}$ and c). Auxin (IAA) oxidized and metabolized swiftly, supporting the formation of shoots and embryos hence low concentration of IAA encourage root growth and retain the apical dominance (George, 1993). Cytokinins contribute a vital role in plant regulation which provokes calli division in the presence of auxin, leading to bud or root formation directly on the explants or from calli (Taiz and Zeiger, 2004). The synergistic effect of auxins and cytokinins has also been reported in other Ocimum spp. (Phippen and Simon, 2000; Singh and Sehgal 1999; 
Patnaik and Chand, 1996; Vasil and Thorpe, 1994; Evans et al., 1981). In the same medium, rooting was vigorous when the shoots were placed in medium supplemented with IAA and BAP in combination. The number of roots induced was $15.00 \pm 0.23$ having average root length $6.05 \pm 0.06 \mathrm{~cm}$ (Table 3). New individual plantlets propagated well from axillary buds on further multiplication (Fig. 1d).

Acclimatization. Regenerated shoots having vigorous roots from rooting media were transferred to green house for acclimatization. Three different types of potting mix (soil, charcoal and farm yard manure) were used in different ratio as shown in Table 4. In order to study the phenotypic variation of in-vitro propagated plantlets in ex-vitro conditions. In this experimental design, it is observed that the A7 media containing Soil: FYM at the ratio of $75: 25$ showed $87 \%$ survival rate and plantlets were healthy and green with normal
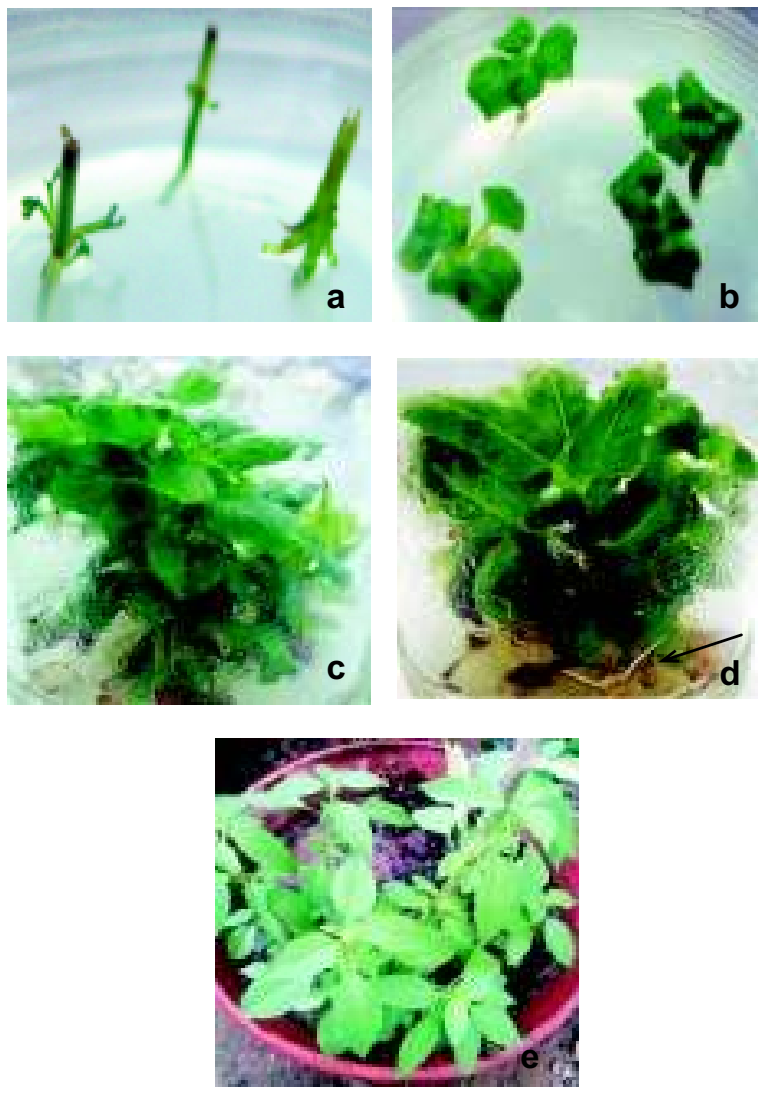

Fig. 1. Direct regeneration in Ocimum sanctum (a) budding of nodal segments after one week (b) plantlet formation after three weeks (c) shoot multiplication (d) rooting (arrow) and plantlet formation (e) acclimatized plant. proliferation, whereas A1 media containing 100\% sand also exhibited optimum growth for the acclimatization and hardening of Ocimum sanctum, albeit the foliage colour was on the lighter green shade. Previous reports showed that acclimated plants survival under ex vitro condition ranges from $70 \%$ (Begum et al., 2000) to $85 \%$ (Singh and Sehgal, 1999), but as the waxy cuticle layer of young plants develop, they become more resistant to environmental stresses (Khan et al., 2007).

\section{Conclusion}

In this study, the identical plantlets of $O$. sanctum were produced in massive quantity from nodal segment which reveal that direct regeneration is more efficient than indirect (callus) regeneration method. Shoots were vigorously propagated from nodal segment under invitro conditions, which lead to root proliferation on optimized MS medium supplemented with Growth regulators (BAP and IAA) respectively. This study is concluded with the approach for producing the identical plantlets of $O$. sanctum in immense number from nodal segments.

Conflict of Interest. The authors declare no conflict of interest.

\section{References}

Begum, F., Amin, N., Azad, A.K. 2000. In-vitro clonal propagation of holy basil-Ocimum sanctum L. Plant Tissue Culture, 10: 31-37.

Bhattacharyya, R., Bhattacharya, S. 2001. High frequency in vitro propagation of Phyllanthus amarus Schum. and Thom. by shoot tip culture. Indian Journal of Experimental Biology, 39: 1184-1187.

Chattopadhyay, R.R., Sarkar, S.K., Ganguly, S., Medda, C., Basu, T.K., 1992. Hepatoprotective activity of Ocimum sanctum leaf extract against paracetamol induced hepatic damage in rats. Indian Journal of Pharmacology, 24: 163-165.

De Klerk, G.J., Ter Brugge, J., Marinova, S. 1997. Effectiveness of indole acetic acid, indole butyric acid and naphthalene acetic acid during adventitious root formation in vitro in Malus 'Jork 9'. Plant Cell, Tissue and Organ Culture, 49: 39-44.

Dharmani, P., Kuchibhotla, V.K., Maurya, R., Srivastava, S., Sharma, S., Palit, G. 2004. Evaluation of antiulcerogenic and ulcer-healing properties of Ocimum sanctum Linn. Journal of Ethnopharmacology, 93: 197-206.

Evans, D.A., Sharp, W.R., Flick, C.E. 1981. Growth and behaviour of cell cultures; embryogenesis and 
organogenesis. In: Plant Tissue Culture; Methods and Application in Agriculture, Thorpe, T.A. (ed.), pp. 45-113, Academic Press, New York, USA.

Fontanay, S., Grare, M., Mayer, J., Finance, C., Duval, R.E. 2008. Ursolic, oleanolic and betulinic acids: antibacterial spectra and selectivity indexes. Journal of Ethnopharmacology, 120: 272-276.

George, E.F. 1993. Plant Propagation by Tissue Culture, vol. 1, 2nd edition, London,UK.

Gopi, C., Sekhar, Y.N., Ponmurugan, P. 2006. In vitro multiplication of Ocimum gratissimum L. through direct regeneration. African Journal of Biotechnology, 5: 723-726.

Hannan, J.M.A., Ojo, O.O., Ali, L., Rokeya, B., Khaleque, J., Akhter, M., Abdel-Wahab, Y.H.A. 2015. Actions underlying antidiabetic effects of Ocimum sanctum leaf extracts in animal models of Type 1 and Type 2 diabetes. European Journal of Medicinal Plants, 5: 1-12.

Jeba, R.C., Vaidyanathan, R., Rameshkumar, G. 2011. Immunomodulatory activity of aqueous extract of Ocimum sanctum in rat. International Journal of Pharmaceutical and Biomedical Research, 2: 33-38.

Khan, S., Naseeb, S., Ali, K. 2007. Callus induction, plant regeneration and acclimatization of African violet (Saintpaulia ionantha) using leaves as explants. Pakistan Journal of Botany, 39: 1263-1268.

Khan, S., Raziq, M., Kayani, H.A. 2008. In-vitro propagation of Bird's nest Fern (Asplenium nidus) from spores. Pakistan Journal of Botany, 40: 91-97.

Khanna, N., Bhatia, J. 2003. Antinociceptive action of Ocimum sanctum (Tulsi) in mice: possible mechanisms involved. Journal of Ethnopharmacology, 88: 293-296.

Kothari, S.K., Bhattacharya, A.K., Ramesh, S. 2004. Essential oil yield and quality of methyl eugenol rich Ocimum tenuiflorum L. (syn. O. sanctum L.) grown in south India as influenced by method of harvest. Journal of Chromatography A, 1054: 67-72.

Kumar, M.S., Rao, M.V. 2007. In vitro micropropagation of Heliotropium indicum Linn. - an ayurvedic herb. Indian Journal of Biotechnology, 6: $245-249$

Kumar, V., Andola, H.C., Lohani, H., Chauhan, N. 2011. Pharmacological review on Ocimum sanctum Linnaeus: a queen of herbs. Journal of Pharmaceutical Research, 4: 336-338.

Mallick, P. 2014. Anti-inflammatory activities of sieboldogenin from Ocimum sanctum: experimental and computational studies. World Journal of Pharmacy and Pharmaceutical Sciences, 3: 1459-1465.

MSTAT Development Team, 1989. MSTAT User's Guide: A Microcomputer Program for the Design, Management and Analysis of Agronomic Research Experiments. Michigan State Univ., East Lansing, USA.

Murashige, T., Skoog, F. 1962. A revised medium for rapid growth and bio-assays with tobacco tissue cultures. Physiologia Plantarum, 15: 473-497.

Pattnaik, S., Chand, P.K. 1996. In vitro propagation of the medicinal herbs Ocimum americanum L. syn. O. canum Sims. (hoary basil) and Ocimum sanctum L. (holy basil). Plant Cell Reports, 15: 846-850.

Phippen, W.B., Simon, J.E. 2000. Shoot regeneration of young leaf explants from basil (Ocimum basilicum L.). In-vitro Cellular Developmental Biology - Plant Journal, 36: 250-254.

Preece, J.E. 1995. Can nutrient salts partially substitute for plant growth regulators? Plant Tissue Culture and Biotechnology, 1: 26-37.

Rajeswari, S. 1992. Ocimum sanctum. The Indian home remedy. In: Current Medicinal Science, S. Rajeswari (eds.), 1st edition, Cipla Ltd., Bombay, India.

Sen, P. 1993. Therapeutic potential of tulsi: from experience to facts. Drugs Views and Views, 1: 1521.

Shanmugam, M.K., Dai, X., Kumar, A.P., Tan, B.K., Sethi, G., Bishayee, A. 2013. Ursolic acid in cancer prevention and treatment: molecular targets, pharma-cokinetics and clinical studies. Biochemical Pharmacology, 85: 1579-1587.

Singh, N.K., Sehgal, C.B. 1999. Micropropagation of 'holy basil' (Ocimum sanctum Linn.) from young inflorescences of mature plants. Plant Growth Regulation, 29: 161-166.

Taiz, L., Zeiger, E. 2004. Metabólitos secundários e defesa vegetal. Fisiologia Vegetal, 3: 309-334.

Triveni, K.K., Singh, A.K., Kumar, R., Gupta, V., Tripathi, K. 2013. Ocimum sanctum Linn: a review on phytopharmacology and therapeutic potential of tulsi. International Journal of Pharmaceutical and Phytopharmacological Research, 3: 148-151.

Vasil, I.K., Thorpe, T.A. 1994. In: Plant Cell and Tissue Culture. Vasil, I.K., Thorpe, T.A. Springer.

Zafar, S., Yousuf, S., Kayani, H.A., Saifullah, Khan, S., Al-Majid, A., Choudhary, M.I. 2012. Biotransformation of oral contraceptive ethynodiol diacetate with microbial and plant cell cultures. Chemistry Central Journal, 6: 109-116. 